\title{
BMJ Open SporTRIA study-a multicentre trial protocol for excretion kinetics of triamcinolone acetonide following sport-related intra-articular injections in knees: definitions of the washout periods
}

\author{
Edem Allado (D) ,1,2 Mathias Poussel (D) , ${ }^{1,2}$ Nicolas Gambier, ${ }^{3,4}$ Véronique Saunier, ${ }^{5}$ \\ Marjorie Starck, ${ }^{5}$ Corinne Buisson, ${ }^{6}$ Gael Cinquetti, ${ }^{7}$ Eliane Albuisson, ${ }^{5,8}$ \\ Bruno Chenuel ${ }^{1,2}$
}

To cite: Allado E, Poussel M Gambier N, et al. SporTRIA study —a multicentre trial protocol for excretion kinetics of triamcinolone acetonide following sport-related intra-articular injections in knees: definitions of the washout periods. BMJ Open 2021;11:e047548. doi:10.1136/ bmjopen-2020-047548

- Prepublication history for this paper is available online. To view these files, please visit the journal online (http://dx.doi org/10.1136/bmjopen-2020047548).

Received 01 December 2020 Accepted 25 May 2021

Check for updates

(c) Author(s) (or their employer(s)) 2021. Re-use permitted under CC BY-NC. No commercial re-use. See rights and permissions. Published by BMJ.

For numbered affiliations see end of article.

Correspondence to

Dr Edem Allado;

e.allado@chru-nancy.fr

\section{ABSTRACT}

Introduction Intra-articular (IA) and peri-articular glucocorticoid (GC) injections are common in sports medicine. However, from 1 January 2022, all injectable GC routes (including IA administration) will be prohibited incompetition by World Anti-Doping Agency (WADA). Owing to these rules, an IA GC treatment out-of-competition could result in an adverse analytical finding in-competition if the washout period is not clearly defined. The aim of this study is to determine the urinary excretion profile of triamcinolone acetonide following IA injection to strengthen the definition of the washout periods. Methods and analysis This is a prospective multicentre trial to include 20 subjects who practice sports for at least 4 hours/week and present a knee disorder requiring IA injection of triamcinolone acetonide for therapeutic purposes. To determine the excretion profile of triamcinolone acetonide in both urine and blood following IA injection of the drug, We will perform 20 urinary tests and 20 dried blood spot tests, two prior to GC injection (baseline) and the last one at 35 days. Analyses will be performed by the French antidoping agency laboratory in accordance with WADA standards and regulations.

Ethics and dissemination The study protocol was approved by the French ethics committee (CPP Sud Est III-Lyon-2020-070B on 06 October 2020). All subjects will provide written informed consent. The results of this study will be accessible in peer-reviewed publication and be presented at academic conference.

Trial registration number NCT04574232.

\section{INTRODUCTION}

Therapeutic use of intra-articular (IA) or peri-articular glucocorticoid (GC) injection is frequent in sports medicine and is subject to strict rules according to the World AntiDoping Agency (WADA). ${ }^{1-4}$ Local GC injections are commonly used to treat sports injuries. In particular, they are used to relieve
Strengths and limitations of this study

This study determines the excretion profile of triamcinolone acetonide in urine following intra-articular (IA) glucocorticoid injection.

- Analysis from a dried blood spot test will be used to precise reporting value in the blood matrix after an IA treatment.

- Biological analyses will be performed by a laboratory accredited by World Anti-Doping Agency.

- A limitation of the study is the absence of documentation of diet, fluid intake and kidney function.

- Another limitation of the study is the lack of result stratification according to the sport type and the conditions of physical activity.

pain and allowing better rehabilitation. ${ }^{5}$ In addition, they provide effective management of musculoskeletal disorders such as synovitis, osteoarthritis, bursitis, tendinitis and others. ${ }^{6}$

GCs are currently prohibited in-competition when administered by systemic routes (orally, intravenously, intramuscularly or rectally) according to the 2021 WADA list of prohibited substances and methods. In addition, WADA Executive Committee approved in the September 2020 meeting that all injectable routes of administration of GCs will be prohibited in-competition. These new rules will come into effect from 1 January $2022 .^{78}$ The 1-year period is expected to allow athletes and medical personnel to get a better understanding of the practical implementation of the washout periods and sports authorities to develop educational tools for athletes, medical and support personnel, addressing the safe use of GC for clinical purposes in 
antidoping. Indeed, the ergogenic effects of GCs are the subject of debate in the literature. ${ }^{9}$ Some studies describe a positive effect regarding exhaustion, perception of fatigue and endurance performance while others suggest that GCs have no systemic effect on performance. ${ }^{10-14}$ In addition, GCs have for some years been placed on the WADA monitoring programme for out-of-competition use.

The elimination kinetics of GCs are known for most products used orally, there is less clarity in the literature when GCs are administered as an injection, even more so when it is not ultrasound-guided or radio-guided. ${ }^{815-18}$ Studies describing elimination profiles of triamcinolone acetonide after intramuscular and IA administration and triamcinolone hexacetonide (excreted in urine as triamcinolone acetonide and metabolites) after IA injection have been described in detail. ${ }^{17}{ }^{19-22}$ In addition, a recent review of the literature showed a urinary detection period of triamcinolone acetonide ranging from 3 to 8 days after the IA injection, in limited groups of up to eight people. ${ }^{22}$

During the Olympic Games in Rio (2016), a register specially created to report on the therapeutic injections performed found that there was significant use of GC injections. ${ }^{1}$ Medical doctors, sports and exercise physiologist and sports organisations experts (eg, Fédération Internationale de Football Association and International Cycling Union) have already reported on the excessive use of GC injections prior to competitions, a procedure which is not without consequences to health. ${ }^{23} 24$

In that peculiar context of the implementation of the new antidoping rules, introducing the prohibition of all injectable GC routes during the in-competition period, it is crucial to clarify the excretion profile of triamcinolone acetonide in urine (and blood) following IA injection of the drug to help in the definition of the washout periods.

\section{METHODS}

\section{Design and study population}

This is to be an open, prospective, multicentre study involving two French hospitals (University Hospital of Nancy and Army Hospital of Metz). We will include 20 patients who have sports practice of at least 4 hours/ week and who suffer from a knee pathology requiring GC IA injection therapy (triamcinolone acetonide). Only patients with negligible triamcinolone acetonide concentrations in urine $(\mathrm{eg},<1 \mathrm{ng} / \mathrm{mL}$ ) will be accepted to participate, to avoid results due to accumulation of the drug produced by previous administrations. Main eligibility criteria are summarised in table 1 . Biological antidoping samples are collected before and after the IA GC injection and periodically over the course of 35 days.

\section{Protocol: research progress}

The study is to be initiated from January 2021 with an anticipated end for subject recruitment in January 2023. Study completion is scheduled for June 2023.

\begin{tabular}{ll}
\hline \multicolumn{2}{l}{ Table $1 \quad$ Inclusion and exclusion criteria } \\
\hline Inclusion criteria & Exclusion criteria \\
\hline $\begin{array}{l}\text { Sports practice at least } \\
4 \text { hours/week }\end{array}$ & $\begin{array}{l}\text { Subject with GC allergy or GC } \\
\text { medical contraindication }\end{array}$ \\
$\begin{array}{ll}\text { No comorbidities } \\
\text { against indicating intra- } \\
\text { articular knee injection }\end{array}$ & $\begin{array}{l}\text { Pregnant women or women of } \\
\text { effective contraception }\end{array}$ \\
$\begin{array}{l}\text { Subject with a knee } \\
\text { disease requiring intra- } \\
\text { articular injection of } \\
\text { GCs }\end{array}$ & $\begin{array}{l}\text { Washout period of all injectable } \\
\text { months }\end{array}$ \\
\hline
\end{tabular}

GCs, glucocorticoids.

Subjects will be included following a sports medicine or rheumatology appointment after validation of inclusion criteria (table 1). At baseline, before and after performing the GC IA injection, under careful aseptic conditions and with ultrasound guidance, a series of biological antidoping samples will be collected (urinary, dried blood spot (DBS) and hair). The same biological samples will then be regularly collected by the patient during the 35 days of follow-up according to the schedule described in table 2. A clinical research nurse will be in regular contact with patients to remind them of the days and progress of biological specimen collection. At the end of the study, 20 urinary samples, 20 DBS samples and 2 locks of hair will be studied.

All biological samples will be sent to the Lorraine Biological Resource Center (CRB Lorraine-BB-0033-00035) in compliance with ISO 9001:2015 and NFS 96-900:2011 standards. This biobanking centre will ensure the preparation and storage of biological samples and the sending of samples for assaying to the French Anti-Doping Laboratory (Agence Française de Lutte contre le DopageAnalyses Department) but hair samples will be handled by the Department of Clinical Pharmacology and Toxicology (Centre Hospitalier Régional Universitaire de Nancy) in accordance with the study procedures. The frozen samples will be kept for a period of 10 years.

During the 35 days of follow-up, all patients should report any adverse events to the investigating team via a single dedicated phone number.

\section{Laboratory protocol}

The antidoping tests performed prior to after the injection under ultrasound control will be analysed using the following methodology:

Urinary sample: $90 \mathrm{~mL}$ of urine will be collected in a single container by test. According to the WADA technical documentation (TD2019MRPL, May 2019), a sample with GC urinary concentration $>30 \mathrm{ng} / \mathrm{mL}$ is considered as an adverse analytical finding. In line with new antidoping rules in force on 1 January 2022, GC urinary concentration $>15 \mathrm{ng} / \mathrm{mL}$ will also be considered. ${ }^{25}$ The urine samples will be analysed according to internal accredited protocols routinely used as initial testing procedure. 
Table 2 Schedule of collection

\begin{tabular}{|c|c|c|c|}
\hline Date & $\begin{array}{l}\text { Urinary } \\
\text { sample }\end{array}$ & $\begin{array}{l}\text { Blood } \\
\text { sample by } \\
\text { DBS }\end{array}$ & $\begin{array}{l}\text { Hair } \\
\text { sample }\end{array}$ \\
\hline DO (before injection) & + & + & + \\
\hline D0 (after injection) & + & + & \\
\hline D1 (H0+H24 max) & + & + & \\
\hline $\mathrm{D} 2(\mathrm{H} 0+\mathrm{H} 48$ max $)$ & + & + & \\
\hline D3 (H0+H72 max) & + & + & \\
\hline D4 (H0+H96 max) & + & + & \\
\hline D5 (D0+5 days) & + & + & \\
\hline D6 (D0+6 days) & + & + & \\
\hline D7 (D0+7 days) & + & + & \\
\hline D8 (D0+8 days) & + & + & \\
\hline D9 (D0+9 days) & + & + & \\
\hline D10 (D0+10 days) & + & + & \\
\hline D11 (D0+11 days) & + & + & \\
\hline D13 (D0+13 days) & + & + & \\
\hline D15 (D0+15 days) & + & + & \\
\hline D17 (D0+17 days) & + & + & \\
\hline D19 (D0+19 days) & + & + & \\
\hline D21 (D0+21 days) & + & + & \\
\hline D28 (D0+28 days) & + & + & + \\
\hline D35 (D0+35 days) & + & + & \\
\hline
\end{tabular}

The patient collects a total of 20 urinary samples and 20 DBS samples and makes 2 collections of hair locks. DBS, dried blood spot.

Analytical conditions are close to those described by Pereira et al. ${ }^{26}$ Briefly, for the direct detection of GCs, the sample treatment will be carried out on Evolute Express CX $(30 / 3 \mathrm{~mL}$, Biotage, Sweden) cartridges with acetonitrile/methanol/aqueous ammonia (25\%; 50/50/5, $\mathrm{v} / \mathrm{v} / \mathrm{v})$ for elution. Analyses will be performed on an ultra-high-performance liquid chromatography U3000 system coupled to a QExactive+ (Thermo Fisher Scientific, USA).

Blood sample: A collection of DBS obtained after a fingertip capillary prick will be analysed to establish the correlation between urinary and blood excretion of GCs. Moreover, we will measure cortisol levels in DBS to evaluate any systemic effect. Indeed, only urinary criteria are currently available for antidoping laboratories and clinical studies are still needed to establish blood criteria (TDDBS 2021) ${ }^{27}{ }^{28}$ A specific protocol will be implemented in the laboratory for this purpose based on an already published protocol. ${ }^{29}$ Briefly, after a first step of desorption with an organic solvent such as methanol and tert-butyl methyl ether, the extract will be analysed by mass spectrometry.

Hair sample: A lock of hair cut from the vertex posterior region as close as possible to the skin and with a diameter of approximately $5 \mathrm{~mm}$ will be collected. The sample treatment of the hair will be performed according to the method described by Gaillard et al. ${ }^{30}$ The analyses will be realised by ultra-high performance liquid chromatography Nexera X2 (Shimadzu, Japan) linked to a $6500+$ QTRAP triple quadrupole (Sciex, USA).

\section{Primary endpoint}

- Determination of the excretion profile of triamcinolone acetonide in urine following IA ultrasoundguided injection.

\section{Secondary endpoints}

- Modelling of the excretion profile of triamcinolone acetonide in urine following IA ultrasound-guided injection.

- Determination of the excretion profile of cortisol in urine following IA ultrasound-guided injection to evaluate systemic effect.

- Determination of the excretion profile of triamcinolone acetonide in DBS antidoping test following IA ultrasound-guided injection.

- Modelling of the excretion profile of triamcinolone acetonide in DBS antidoping test following IA ultrasound-guided injection.

- Determination of cortisol levels in DBS to evaluate systemic effect.

- Identification of GCs on hair mark present 1 month after IA ultrasound-guided injection of triamcinolone acetonide.

- Evaluation of the impact of exogenous corticosteroids on endogenous steroids profile (androgens and GCs) in DBS samples.

\section{Statistical analysis}

Descriptive analyses will be conducted according to the nature and the distribution of the variables. Qualitative variables are described with frequencies and percentages; quantitative variables are reported as mean $\pm \mathrm{SD}$. Delay mean values will be calculated with their $95 \%$ CIs. Studies of relation and of association will be conducted. For excretion profile, we will use curve fitting to choose the best model for the analysis.

\section{Sample size}

It is a pilot study. The inclusion of 20 patients is envisaged to be in accordance with the potential for recruitment. We are considering the possibility of at least two subjects with a value above WADA standards $(<30 \mathrm{ng} / \mathrm{mL})$ at baseline which will not be included for the primary or secondary endpoints. However, they will be integrated into the kinetics analysis and will be identifiable there.

\section{Data management}

Before the launch of this pilot study, all investigators and members of the investigative team took part in good clinical practice workshops. The sponsor's clinical research associates from the University Hospital of Nancy (France) will perform periodic monitoring in each centre throughout the trial. The data required to meet the 
research objectives will be collected in case report forms (CRFs) specifically designed for this study and will come from the patient's medical records and the results of the analysis of biological samples.

A database will be created specifically for this study and will use the double entry method. To ensure data quality and data concordance, two data entry technicians will independently feed data from the CRFs into the database. If inconsistencies are detected, a third investigator will decide on the data to be entered. The data manager will send queries to the investigative teams to correct or confirm outliers. Before any decision to freeze the database and to ensure a clean database, all CRF data will be incorporated into the database and all queries will be resolved. The final milestone will be the database lock.

The data from all patients will be centrally stored in Nancy. Data management will be carried out by CHRU de Nancy (Direction de la Recherche et de l'Innovation). The conditions for data transfer of all or part of the study database are decided by the study sponsor and are the subject of a written contract. This study and the data collected fall within the scope of Reference Methodology MR001.

The data may be transmitted to the companies in the group to which the promoter belongs and to its contractual partners in a form which should not permit the direct or indirect identification of persons lending themselves to research.

\section{DISCUSSION}

The results of this pilot study will identify the blood and urinary excretion profiles of triamcinolone acetonide following IA injection of the drug (primary endpoint) and will also provide complementary data to establish potential reporting values for GCs in DBS in connection with the urinary concentrations. These information are essential for the antidoping community to strengthen the washout periods, recommended to athletes after an IA treatment during out-of-competition periods close to competitions. This study will help to get a better understanding of the practical implementation of the washout periods but also to confirm reporting limits applied by antidoping laboratories. To consider this point, experts must have kinetic reference values and GC peak urinary and blood concentration evolution after IA injection.

To date, although there is no consensus on the potential consequences of their possible ergogenic effect, GCs are one of the most frequently detected substances in antidoping tests. ${ }^{9}$ Their deleterious impact on athlete's health (bone tissue, muscle tissue, metabolism and cardiovascular system) justifies their presence on the WADA list of prohibited substances and methods of administration $^{24}{ }^{31-33}$ However, the benefit-risk balance is oriented in favour of the introduction of GCs for therapeutic purposes for some diseases (eg, endocrine disorders and rheumatic disorders). To allow athletes in competition who have these types of pathologies and require systemic administration of a WADA prohibited substance such as GCs, a therapeutic use exemption (TUE) must be obtained. The TUE request can be submitted for competent expert assessment of the indication of treatment and may be proactive, before start of treatment, or retroactive, after treatment has started. In this latter case, TUE often follows an adverse analytical finding, with the risk of a refusal from experts and the initiation of proceedings from a disciplinary commission. In addition, a recent study by Vernec $e t a t$ found that the retroactive TUE percentage (taken from the WADA ADAMS database for 2012-2016) was 21\% for all substances against $39 \%$ for GCs alone. These results highlight the highly extensive use of GCs and argue for the need for further research, clarifying when the use is for therapeutic purposes and when for ergogenic effect.

\section{Ethics and dissemination}

This study received approval from the French ethics committee (CPP Sud Est III-Lyon-2020-070B on 06 October 2020) and has been registered with the French competent authority (ANSM-no. ID-RCB: 2020-A01448-31).

It will be conducted according to the European good clinical practice recommendations, the general ethical principles of the declaration of Helsinki and specific French regulations.

Before inclusion, each patient will receive, both verbally and in writing, a full brief on the study objectives, its progress, and its constraints, before giving their written consent to participate in the trial.

\section{Patient and public involvement}

Patients and the public were not involved in the design or planning of the study

\section{Potential amendments}

We do not plan to modify the protocol to avoid reporting bias. However, if necessary, any amendment in the review process will be reported for transparency.

\section{Author affiliations}

${ }^{1}$ Université de Lorraine, CHRU-Nancy, University Centre of Sports Medicine and Adapted Physical Activity, Centre Hospitalier Régional Universitaire de Nancy, Nancy, Lorraine, France

${ }^{2}$ Université de Lorraine, DevAH, Université de Lorraine, Nancy, Lorraine, France ${ }^{3}$ Université de Lorraine, CHRU-Nancy Department of Clinical Pharmacology and Toxicology, Centre Hospitalier Régional Universitaire de Nancy, Nancy, Lorraine, France

${ }^{4}$ Université de Lorraine, CNRS, IMoPA, Université de Lorraine, Nancy, Lorraine, France

${ }^{5}$ CHRU-Nancy, Direction de la Recherche Clinique et de l'Innovation, Centre Hospitalier Régional Universitaire de Nancy, Nancy, Lorraine, France ${ }^{6}$ Département des Analyses, AFLD, AFLD, Chatenay-Malabry, Île-de-France, France ${ }^{7}$ Service des Maladies Infectieuses et Systémiques, Hôpital d'Instruction des Armées Legouest, Metz, Lorraine, France

${ }^{8}$ Université de Lorraine, CNRS, IECL, Université de Lorraine, Nancy, Lorraine, France

Acknowledgements The sponsor was CHRU de Nancy (Direction de la Recherche et de l'Innovation). The authors thank Magnus Ericsson for his help for manuscript reviewing. 
Contributors $\mathrm{BC}$ and EAll had the original idea. BC, EAlb and EAll designed and conceived the protocol. BC, MP and EAll drafted the manuscript. BC, NG, VS, MS, $\mathrm{CB}, \mathrm{GC}$ and EAlb critically revised the manuscript for methodology and intellectual content. All authors approved the final version of this manuscript.

Funding This study was supported by a grant (number N/A) from the French AntiDoping Agency (Agence Française de Lutte contre le Dopage (AFLD)).

Competing interests None declared.

Patient and public involvement Patients and/or the public were not involved in the design, or conduct, or reporting, or dissemination plans of this research.

Patient consent for publication Obtained.

Provenance and peer review Not commissioned; externally peer reviewed.

Open access This is an open access article distributed in accordance with the Creative Commons Attribution Non Commercial (CC BY-NC 4.0) license, which permits others to distribute, remix, adapt, build upon this work non-commercially, and license their derivative works on different terms, provided the original work is properly cited, appropriate credit is given, any changes made indicated, and the use is non-commercial. See: http://creativecommons.org/licenses/by-nc/4.0/.

\section{ORCID iDs}

Edem Allado http://orcid.org/0000-0002-1760-6979

Mathias Poussel http://orcid.org/0000-0002-4386-8606

\section{REFERENCES}

1 Allen M, Stuart MC, Gribble H, et al. Needle-use declarations at the Olympic Games Rio 2016. Br J Sports Med 2018;52:747-52.

2 Rochcongar P. L'utilisation et La prescription des corticoïdes en médecine Du sport. Sci Sports 2005;20:197-8.

3 Collomp K, Arlettaz A, Buisson C, et al. Glucocorticoid administration in athletes: performance, metabolism and detection. Steroids 2016;115:193-202.

4 Vernec A, Slack A, Harcourt PR, et al. Glucocorticoids in elite sport: current status, controversies and innovative management strategies-a narrative review. Br J Sports Med 2020;54:8-12.

5 Brinks A, Koes BW, Volkers ACW, et al. Adverse effects of extraarticular corticosteroid injections: a systematic review. BMC Musculoskelet Disord 2010;11:206.

6 Lavelle W, Lavelle ED, Lavelle L. Intra-Articular injections. Med Clin North Am 2007:91:241-50.

7 World Anti-Doping Agency. 2021 Prohibited List - Summary of major modifications and explanatory notes 2021.

8 World Anti-Doping Agency. List of prohibited substances and methods, 2021. Available: www.wada-ama.org

9 Duclos M. Glucocorticoids: a doping agent? Endocrinol Metab Clin North Am 2010;39:107-26.

10 Collomp K, Arlettaz A, Portier H, et al. Short-Term glucocorticoid intake combined with intense training on performance and hormonal responses. Br J Sports Med 2008;42:983-8.

11 Kuipers H, Hullenaar GACV, Pluim BM, et al. Four weeks' corticosteroid inhalation does not augment maximal power output in endurance athletes. Br J Sports Med 2008;42:568-71.

12 Baume N, Steel G, Edwards T, et al. No variation of physical performance and perceived exertion after adrenal gland stimulation by synthetic ACTH (synacthen) in cyclists. Eur J Appl Physiol 2008;104:589-600.
13 Le Panse B, Thomasson R, Jollin L, et al. Short-Term glucocorticoid intake improves exercise endurance in healthy recreationally trained women. Eur J Appl Physiol 2009;107:437-43.

14 Soetens E, De Meirleir K, Hueting JE. No influence of ACTH on maximal performance. Psychopharmacology 1995;118:260-6.

15 Chen T-T, Tseng Y-C, Huang T-Y, et al. Elimination profile of triamcinolone in urine following oral administration. Drug Test Anal 2018;10:860-4.

16 Kaliszewski P, Kończak D, Chołbiński P, et al. Budesonide treatment of professional athletes and anti-doping testing--case studies. Acta Pol Pharm 2016;73:229-37.

17 Matabosch X, Pozo OJ, Pérez-Mañá C, et al. Evaluation of the reporting level to detect triamcinolone acetonide misuse in sports. $J$ Steroid Biochem Mol Biol 2015;145:94-102.

18 Jones A, Regan M, Ledingham J, et al. Importance of placement of intra-articular steroid injections. BMJ 1993;307:1329-30.

19 Coll S, Matabosch X, Llorente-Onaindia J, et al. Elimination profile of triamcinolone hexacetonide and its metabolites in human urine and plasma after a single intra-articular administration. Drug Test Anal 2019;11:1589-600.

20 Coll S, Monfort N, Alechaga Élida, et al. Additional studies on triamcinolone acetonide use and misuse in sports: elimination profile after intranasal and high-dose intramuscular administrations. Steroids 2019;151:108464.

21 Chang C-W, Huang T-Y, Tseng Y-C, et al. Positive doping results caused by the single-dose local injection of triamcinolone acetonide. Forensic Sci Int 2014;244:1-6.

22 Ventura R, Daley-Yates P, Mazzoni I, et al. A novel approach to improve detection of glucocorticoid doping in sport with new guidance for physicians prescribing for athletes. Br J Sports Med 2021;55:631-42.

23 Fitch K. Glucocorticoids at the Olympic games: state-of-the-art review. Br J Sports Med 2016;50:1267

24 Pigozzi F, Di Gianfrancesco A, Zorzoli M, et al. Why glucocorticosteroids should remain in the list of prohibited substances: a sports medicine viewpoint. Int $J$ Immunopathol Pharmacol 2012;25:19-24.

25 World Anti-Doping Agency. Minimum required performance levels for detection and identification of non-threshold substances, 2019. Available: www.wada-ama.org

26 Pereira HMG, Sardela VF, Padilha MC, et al. Doping control analysis at the Rio 2016 Olympic and Paralympic Games. Drug Test Anal 2017;9:1658-72.

27 Thevis M, Kuuranne T, Dib J, et al. Do dried blood spots (DBS) have the potential to support result management processes in routine sports drug testing? Drug Test Anal 2020;12:704-10.

28 World Anti-Doping Agency. Technical directive dried blood spot (TDDBS), 2021. Available: www.wada-ama.org

29 Thomas A, Geyer H, Schänzer W, et al. Sensitive determination of prohibited drugs in dried blood spots (DBS) for doping controls by means of a benchtop quadrupole/Orbitrap mass spectrometer. Anal Bioanal Chem 2012;403:1279-89.

30 Gaillard Y, Vayssette F, Pépin G. Compared interest between hair analysis and urinalysis in doping controls. Forensic Sci Int 2000;107:361-79.

31 Nussinovitch U, de Carvalho JF, Pereira RMR, et al. Glucocorticoids and the cardiovascular system: state of the art. Curr Pharm Des 2010;16:3574-85.

32 Schakman O, Gilson H, Kalista S, et al. Mechanisms of muscle atrophy induced by glucocorticoids. Horm Res 2009;72 Suppl 1:36-41.

33 Compston J. Glucocorticoid-Induced osteoporosis: an update. Endocrine 2018:61:7-16. 